\title{
Efficiency and Productivity Growth Comparisons of European and U.S. Air Carriers: A First Look at the Data
}

\author{
DAVID H. GOOD \\ SPEA and INSEAD, Indiana University, Bloomington, IN 47405
}

M. ISHAQ NADIRI

New York University and NBER

LARS-HENDRIK RÖLLER

INSEAD and CEPR

ROBIN C. SICKLES

University of Michigan, Rice University and NBER

\begin{abstract}
In this paper we carry out technical efficiency and productivity growth comparisons among the four largest European carriers and eight of their American counterparts. The time period of our comparisons is 1976 through 1986. This is a particularly interesting period since it begins just after the informal steps toward deregulation in the United States and ends just prior to the introduction of the first wave of reforms by the Council of Ministers in Europe. We also identify the potential efficiency gains of the European liberalization by comparing efficiency differences between the two carrier groups. The reductions in inefficiency describe the amount that inputs can be decreased without altering output.
\end{abstract}

\section{Introduction}

In this paper we carry out technical efficiency and productivity growth comparisons among the four largest European carriers and eight of their American counterparts. The time period of our comparisons is 1976 through 1986 . This is a particularly interesting period since it begins just after the informal steps toward deregulation in the United States and ends just prior to the introduction of the first wave of reforms by the Council of Ministers in Europe. ${ }^{\prime}$ We also identify the potential efficiency gains of the European liberalization by comparing efficiency differences between the two carrier groups. The reductions in inefficiency describe the amount that inputs can be decreased without altering output.

Our analysis also provides a description of the competitive standing of European carriers relative to one another. As such, it is suggestive of the future success of these airlines once the protection of regulation is relaxed. Moreover, one of the most politically vocal sectors affected by widening competition (and its projected effects on inefficiency) will be labor. Our analysis demonstrates that the potential magnitude of cost savings may more than compensate displaced workers. Further, our analysis is useful because it explains why 
some airlines have favored liberalization in Europe, such as British Air, while others have been opposed to it.

In the next section we describe the data sources and variable constructions. Section 3 describes alternative estimation procedures for identifying the temporal patterns of inefficiency over the study period. The procedures differ in assumptions regarding the correlation of firm-specific efficiency with factor inputs and other explanatory variables. Estimates are discussed in Section 4 with particular emphasis on their implications for the extent of resource displacement which would result were European carriers to perform at the same level as the deregulated American carriers. The last section provides summary and concluding remarks.

\section{Data}

Our airline data set consists of a panel of the four largest European carriers: Air France, Alitalia, British Air, and Lufthansa, and the eight largest American airlines: American, Continential, Delta, Eastern, Northwest, Pan Am, TWA, and United. These four European carriers supply approximately half of the international traffic of all airlines based in Europe. The eight U.S. carriers supply virtually all of the scheduled international traffic of the U.S. airline industry. We follow these carriers with annual observations during the period 1976 to 1986 . The primary data source is the Digest of Statistics from the International Civil Aviation Organization (ICAO). With this we construct a set of three airline input aggregates: labor, energy/materials, and aircraft fleet. In addition, aggregate airline outputs and several of its characteristics are constructed.

Labor input is an aggregate of five separate categories of employment used in the production of air travel. These categories include pilots, as well as copilots and other cockpit crew, flight attendants, mechanics, ticketing and passenger handlers, and other employees. Information on annual expenditures and the number of employees are available for these categories from ICAO's Fleet and Personnel Series for each year. The discrete approximation to the Divisia multilateral index number is used to aggregate these subcomponents (Caves, Christensen, and Diewert [1982]).

Fuel expenses are given for each carrier in ICAO's Financial Data Series. Unfortunately, there are no carrier specific quantity or price figures given in that source. Contract fuel prices for international traffic in different regions is available through ICAO's Regional Differences in Fares and Costs. The airline's fuel price is then estimated as a weighted average of the domestic fuel price (weighted by domestic available tonne-kilometers), and regional prices (weighted by international available tonne-kilometers in the relevant region). This method explicitly recognizes that for international carriers not all fuel is purchased in the airline's home country. Expenditures on supplies, services and ground based capital equipment and taxes are combined into a residual aggregate. Since the purchasing power of a dollar or its market exchange rate equivalent is not the same in all countries, we use the purchasing power parity exchange rates for the carrier's home country in each year constructed from Heston and Summers [1988]. These are adjusted by allowing for changes in market exchange rates and changes in price levels. Use of airport runways is based on landing fee expenses with aircraft departures as the quantity deflator. The service price 
for owned ground based equipment is constructed using the original purchase price, a $7 \%$ depreciation rate, and the carrier's interest rate on long-term debt. As with the labor input, these subcomponents are aggregated using a multilateral index number procedure. Finally, energy and the residual category are aggregated into the materials input using the multilateral index number procedure.

Detailed information for aircraft fleets is provided in ICAO's Fleet and Personnel Series. In addition to counts of the total number of aircraft, we construct the percentage of the fleet that is wide-bodied, which is a measure of average equipment size, and the percentage of the fleet that is turboprop, which is a measure of aircraft speed.

Information regarding the carrier's output quantities are obtained from ICAO's Commercial Airline Traffic Series. While this source permits several possible disaggregations we consider three components of airline output: passenger service, cargo operations, and incidental services which includes, among other things, equipment leasing and maintenance provided to other carrier's equipment. Revenues for passenger, cargo and incidental outputs as well as explicit subsidies are obtained in ICAO's Financial Data Series. The country's purchasing power parity is used as a price deflator for incidental output. Revenue tonne-kilometers (RTK) is used as a quantity deflator for passenger and cargo outputs. As with the inputs, these three components are aggregated using the multilateral index number procedure.

Three characteristics of airline output are also calculated. These include load factor, stage length, and a measure of network size. Load factor provides a measure of service quality and is a widely used proxy for service competition in most airline transportation studies. Stage length provides a measure of the length of individual route segments in the carrier's network. Finally, the number of route kilometers, from the International Air Transport Association's Statistical Yearbook, provides a measure of total network size. As the number of route kilometers falls, ceteris paribus, route density rises.

A table listing means and standard deviations for American and European variables are in Table 1. One of the more striking differences between these two groups is that while the output of an American carrier is on average 50\% larger than that of a European carrier, there is little difference on average in the levels of employment or materials usage. The number of planes used by European carriers, however, is on average only about half that of U.S. airlines. Europeans have clearly chosen a more labor and materials intensive input

Table 1. Summary statistics.

\begin{tabular}{lrrrr}
\hline \multicolumn{1}{c}{ Variable } & $\begin{array}{c}\text { American } \\
\text { Mean }\end{array}$ & $\begin{array}{c}\text { European } \\
\text { Mean }\end{array}$ & $\begin{array}{r}\text { American } \\
\text { Std. Dev. }\end{array}$ & $\begin{array}{r}\text { European } \\
\text { Std. Dev. }\end{array}$ \\
\hline Aggregate output $\left(1^{\circ}\right)$ & 3075.54 & 2022.64 & 1165.95 & 735.71 \\
Labor (workers) & 30730.76 & 31693.27 & 12435.41 & 10459.30 \\
Materials (106) & 1690.34 & 1610.86 & 569.02 & 649.48 \\
Number of planrs & 220.21 & 108.10 & 85.74 & 37.72 \\
Load factor & 0.60 & 0.62 & 0.04 & 0.03 \\
Stage length (kilometers) & 1295.06 & 1179.70 & 422.65 & 123.48 \\
Percent wide-body aircraft & 24.89 & 24.04 & 12.18 & 16.62 \\
Percent truboprop aircraft & 0.40 & 0.26 & 0.99 & 0.34 \\
Network size (thous. of kilometers) & 302.14 & 489.51 & 117.03 & 143.63 \\
\hline
\end{tabular}


mix than carriers in America. Together with the relatively small differences in load factors and stage length, this may be suggestive of service competition incentives among the European carriers which was extant in the U.S. industry before it was deregulated early in the sample period.

\section{Econometric Estimation}

Our estimates of efficiency differences among international airline carriers are based on a Cobb-Douglas single output technology and can be interpreted in the neoclassical tradition of static long-run equilibrium. While it would be desirable to estimate a flexible form such as the translog, we limit our initial study to more parsimonious forms. ${ }^{2}$ Alternative approaches, such as examining the partial static long-run equilibrium using a variable cost function are not considered here since different objectives of nationalized and private carriers are likely to imply that production decisions are not cost minimizing given market prices for at least some airlines. Multiple output specifications, which include domestic and international traffic or enplanements along with revenue traffic have been considered elsewhere (e.g., Good and Rhodes [1991]) but do not easily lend themselves to the econometric issues considered herein.

Since productive efficiency can be viewed as a residual, we are particularly interested in the specificaton of the error term. Three alternative statistical treatments are considered for the Cobb-Douglas stochastic frontier production model:

$$
y_{i t}=X_{i t} \beta+W_{i t} \delta_{i}+\epsilon_{i t}, \quad \delta_{i}=\delta_{0}+u_{i},
$$

where the subscripts $i=1, \ldots, N$ and $t=1, \ldots, T$ refer to the firm and to time, respectively, $y_{i t}$ is the log of aggregate output, $X_{i t}^{\prime}$ is a $(K)$ vector of log inputs and other firm characteristics at time $t$, and $W_{i t}^{\prime}$ is a $(L)$ vector of explanatory variables which may have different effects for different firms. The unobservable firm effects, $\delta_{i}$, can be correlated with other explanatory variables and can interact with selected slope and intercept terms. This allows us to consider the endogeneity of such variables as load factor to firm specific statistical error. $u_{i}$ is asumed to be an i.i.d. zero-mean random vector with covariance matrix $\Lambda$. The disturbances $\epsilon_{i t}$ are taken to be i.i.d. with zero mean, constant variance $\sigma^{2}$, and to be uncorrelated with both the regressors and $u_{i}$.

The distinguishing feature of this model, developed by Cornwell, Schmidt, and Sickles [1990], over other panel data models (e.g., Hausman and Taylor [1981] is that $W$ has coefficients that depend on $i$. Where $W_{i}$ constant then (1) is the standard panel data firm effect model. In our application, $W$ is expanded to include a time variable $(t)$ which models firm specific productivity growth rates. Consequently, the effect for firm $i$ is $\alpha_{i t}=w_{i t} \delta_{i}=$ $\delta_{i 1}+\delta_{i 2} t$.

It is useful to describe equation (1) in matrix form as

$$
y=X \beta+W \delta_{0}+v, \quad v=Q u+\epsilon,
$$

where $X$ is $N T \times k, W$ is $N T \times L, u$ is $N L \times 1$, and $Q=\operatorname{diag}\left(W_{i}\right), i=1, \ldots, N$, is $N T \times N L$. 
The three statistical treatments we consider are the within, or dummy variables estimator, generalized least square (GLS), and efficient instrumental variables (IV). Denote $P_{Q}$ as the projection onto the column space of $Q$ and $M_{Q}$ as the projection onto the nullspace of $Q$. Let $\left(X_{1}, W_{1}\right)$ indicate the regressors which are exogenous to firm effects and the regressors $\left(X_{2}, W_{2}\right)$ those which are endogenous to the firm effects. The within estimator is IV with instruments $M_{Q}$ and is given by

$$
\hat{\beta}=\left(X^{\prime} M_{Q} X\right)^{-1} X^{\prime} M_{Q} y .
$$

The GLS estimator is

$$
\left[\begin{array}{c}
\hat{\beta} \\
\hat{\delta}_{0}
\end{array}\right]=\left[(X, Q)^{\prime} \Omega^{-1}(X, W)\right]^{-1}(X, W)^{\prime} \Omega^{-1} y
$$

The efficient IV estimator uses instruments $A^{*}=\Omega^{-1 / 2}\left(M_{Q}, X_{1}, W_{1}\right)$ where $\Omega=\operatorname{cov}(v)$ and is given by

$$
\left[\begin{array}{c}
\hat{\beta} \\
\hat{\delta}_{0}
\end{array}\right]=\left(G^{\prime} \Omega^{-1 / 2} P_{A^{*}} \Omega^{-1 / 2} G\right)^{-1} G^{\prime} \Omega^{-1 / 2} P_{A^{*}} \Omega^{-1 / 2} y,
$$

where $G=(X, W)$. The properties of these estimators differ by the extent to which factor inputs and other regressors are endogenous to firm effects, which in the panel stochastic frontier model are interpreted as technical efficiency. If they are exogenous, then GLS is efficient. If any of the regressors are endogenous to the firm effects, then GLS will be inconsistent. However, the within estimator is consistent regardless. If firm effects are endogenous to some, though not all regressors, then some of the efficiency gains of GLS can be obtained by efficient IV without sacrificing the consistency of the within estimator. These estimators are discussed in depth by Cornwell, Schmidt, and Sickles [1990]). The $\delta_{i 1}$ and $\delta_{i 2}$ parameters are estimated by regressing the residuals for firm $i$ on $W_{i t}$. Consistent estimates of the frontier intercept at time $t$ and the firm-specific relative level of technical inefficiency for firm $i$ at time $t, \mu_{i t}$, are

$$
\alpha_{t}=\max _{j}\left(\alpha_{j t}\right), j=1, \ldots, N ; \quad \mu_{i t}=\exp \left[\frac{-\alpha_{t}}{\alpha_{i t}}\right]
$$

For firm $i$, productivity growth at time $t$ is evaluated as the time derivative of $\alpha_{i t}{ }^{3}$

\section{Empirical Results}

In addition to the standard inputs (capital $(K)$, labor $(L)$, and materials $(M)$ ), we augment the production function with several capital, output, and network characteristics (percent turboprop aircraft (PTURBO), percent wide-bodied aircraft (PWIDEB), and load factor (LOADF), stage length (STAGEL), network size (NETSIZE)), time (T), and time-squared.

Parameter estimates for the three treatments of correlations, within, GLS and efficient IV, are given in Table 2. The efficient IV estimator allows efficiency to be correlated with 
Table 2. Parameter estimates for within, GLS, and IV models.

\begin{tabular}{|c|c|c|c|c|c|c|}
\hline \multirow[b]{2}{*}{ Variable } & \multicolumn{2}{|c|}{ Within Estimates } & \multicolumn{2}{|c|}{ Eff. IV Estimates } & \multicolumn{2}{|c|}{ GLS Estimates } \\
\hline & Estimate & $t$ Stat & Estimate & $t$ Stat & Estimate & $t$ Stat \\
\hline Intercept & * & & 1.125 & 2.100 & 1.330 & 2.307 \\
\hline $\ln K$ & 0.349 & 3.411 & 0.339 & 4.266 & 0.360 & 4.741 \\
\hline $\ln L$ & 0.468 & 4.887 & 0.347 & 4.195 & 0.355 & 4.342 \\
\hline $\ln M$ & 0.221 & 2.419 & 0.280 & 3.161 & 0.280 & 3.241 \\
\hline PTURBO & -0.044 & -0.163 & -0.123 & -0.486 & -0.143 & -0.910 \\
\hline PWIDEB & 0.330 & 1.170 & 0.186 & 0.725 & 0.256 & 1.067 \\
\hline In STAGEL & 0.024 & 0.202 & 0.045 & 0.433 & 0.078 & 0.921 \\
\hline In LOADF & 1.048 & 7.435 & 1.053 & 7.500 & 1.048 & 7.970 \\
\hline In NET & -0.065 & -1.041 & -0.034 & -0.647 & -0.055 & -1.219 \\
\hline$T$ & * & & 0.031 & 2.532 & 0.028 & 2.471 \\
\hline$T^{2}\left(\times 10^{2}\right)$ & -0.012 & -0.124 & -0.031 & -0.515 & -0.046 & -0.365 \\
\hline Model adj $R^{2}$ & 0.999 & & 0.987 & & 0.992 & \\
\hline D.W. & 2.091 & & 1.962 & & 1.878 & \\
\hline
\end{tabular}

*The within estimate of the intercept and coefficient on $T$ are not comparable since they depend on the arbitrary choice of which firm dummies to exclude. These parameters are not included in Hausman-Wu tests.

a subset of the regressors. $X_{2}$ contains the output and capital characteristics: PTURBO, PWIDEB, STAGEL, LOADF, and NETSIZE, and $W_{2}$ is a null matrix. The variables in $\mathrm{X}_{2}$ were altered significantly by U.S. carriers during the transition to deregulation and may be endogenous to the level of and growth in efficiency. Empirical evidence (Cornwell, Schmidt, and Sickles [1990]) also points to the endogeneity of these variables.

The three sets of estimates describe production technologies with similar properties. For all three procedures returns to density, whose point estimates range from 1.04 for within to 0.97 for GLS, and returns to scale, whose point estimates from 1.10 for the within model to 1.01 for the GLS model, are insignificantly different from unity to the $1 \%$ level. ${ }^{4}$ Output elasticities for capital fall in the range $[0.34,0.37]$ while those for the energy/materials aggregate and for labor are in the ranges $[0.22,0.28]$ and $[0.35,0.47]$. Estimated elasticities for network and capital characteristics vary across the within, GLS and IV models. The signs of the point estimates are quite plausible although individually they are not statistically significant. Reducing the size of the network increases route density. In general, more output can be produced with the same level of resources over long, dense route structures with larger aircraft.

Since the primary distinction among these techniques is the imposition of othogonality restrictions, the assumptions underlying the GLS and efficient IV estimates can be tested. At conventional significance levels $\left(\chi_{9,0.05}^{2}=16.9\right)$ the Hausman-Wu test leads to a rejection of both the GLS $\left(\chi^{2}=22.5\right)$ and efficient IV $\left(\chi^{2}=20.2\right)$ models for these data in favor of those from the within model which allows for correlation of all regressors with the firm effects. The remainder of our empirical discussion is consequently based on the within estimates.

Technical efficiency estimates are given in Table 3 for each carrier. Table 4 summarizes the European and American efficiency averages as well as productivity growth rates. Among the American carriers, there is generally an increase in efficiency over the study period 
Table 3. Estimate of technical efficiency for within model (percent).

\begin{tabular}{lrrrrrrrrrrr}
\hline \multicolumn{1}{c}{ Airline } & 1976 & 1977 & 1978 & \multicolumn{1}{c}{1979} & \multicolumn{1}{c}{1980} & 1981 & 1982 & 1983 & 1984 & 1985 & 1986 \\
\hline Air France & 65.83 & 66.37 & 66.00 & 65.65 & 65.27 & 64.91 & 64.55 & 64.19 & 63.83 & 63.47 & 63.12 \\
Alitalia & 59.93 & 60.24 & 59.73 & 59.22 & 58.72 & 58.22 & 57.73 & 57.24 & 56.75 & 56.27 & 55.79 \\
American & 73.46 & 74.54 & 74.61 & 74.68 & 74.74 & 74.81 & 74.88 & 74.95 & 75.01 & 75.08 & 75.15 \\
British Air & 58.73 & 60.62 & 61.72 & 62.84 & 63.97 & 65.13 & 66.31 & 67.51 & 68.74 & 69.98 & 71.25 \\
Continental & 76.58 & 78.00 & 78.35 & 78.71 & 79.07 & 79.44 & 79.80 & 80.17 & 80.54 & 80.90 & 81.28 \\
Delta & 73.08 & 74.25 & 74.41 & 74.57 & 74.73 & 74.90 & 75.06 & 75.22 & 75.38 & 75.54 & 75.71 \\
Eastern & 66.89 & 67.81 & 67.79 & 67.77 & 67.75 & 67.74 & 67.72 & 67.70 & 67.69 & 67.67 & 67.65 \\
Lufthansa & 66.62 & 67.02 & 66.49 & 65.97 & 65.46 & 64.94 & 64.43 & 63.93 & 63.43 & 62.93 & 62.44 \\
Northwest & 98.63 & 100.00 & 100.00 & 100.00 & 100.00 & 100.00 & 100.00 & 100.00 & 100.00 & 100.00 & 100.00 \\
Pan Am & 100.00 & 99.65 & 97.95 & 96.27 & 94.62 & 93.01 & 91.41 & 89.85 & 88.31 & 86.80 & 85.32 \\
TWA & 72.32 & 74.12 & 74.93 & 75.74 & 76.57 & 77.41 & 78.25 & 79.10 & 79.96 & 80.84 & 81.72 \\
United & 71.07 & 72.91 & 73.78 & 74.65 & 75.55 & 76.45 & 77.36 & 78.28 & 79.21 & 80.15 & 81.11 \\
\hline
\end{tabular}

Table 4. European and American airline productivity growth rates and technical efficiencies (within estimates).

\begin{tabular}{|c|c|c|c|c|c|}
\hline \multicolumn{3}{|c|}{ Productivity Growth (\%) } & \multicolumn{3}{|c|}{ Technical Efficiencies (\%) } \\
\hline Year & Europe & U.S. & Year & Europe & U.S. \\
\hline 76 & 2.8 & 2.8 & 76 & 62.9 & 77.0 \\
\hline 77 & 2.7 & 2.8 & 77 & 63.8 & 78.2 \\
\hline 78 & 2.7 & 2.8 & 78 & 63.8 & 77.7 \\
\hline 79 & 2.7 & 2.7 & 79 & 64.0 & 78.3 \\
\hline 80 & 2.7 & 2.7 & 80 & 64.0 & 79.0 \\
\hline 81 & 2.6 & 2.6 & 81 & 64.1 & 79.0 \\
\hline 82 & 2.5 & 2.6 & 82 & 64.2 & 79.0 \\
\hline 83 & 2.5 & 2.6 & 83 & 64.2 & 79.2 \\
\hline 84 & 2.6 & 2.6 & 84 & 64.5 & 79.1 \\
\hline 85 & 2.6 & 2.6 & 85 & 64.6 & 79.2 \\
\hline 86 & 2.5 & 2.7 & 86 & 64.7 & 79.4 \\
\hline
\end{tabular}

from an average of $77 \%$ in 1976 to $79.4 \%$ in 1986 (see Table 4). This $0.24 \%$ average annual increase in technical efficiency can be added to the $2.4 \%$ average annual technological change ${ }^{5}$ to yield an average of $2.7 \%$ average annual productivity growth. This reduction in heterogeneity (less efficient firms are converging toward the production frontier) is consistent with the deregulatory process. Firms lost both their protected niches and nonsystematic network restrictions. This was especially true for Pan Am. Pan Am had been the designated U.S. carrier for several European and oriental routes. As a part of the deregulatory process, the United States began to open its international routes to other carriers. Without any firm feeder network within the United States (only a very limited network concentrated in New England was provided by the acquisition of National in 1979), Pan Am was severely disadvantaged, and ultimately sold its oriental routes to United in 1986. Northwest, on the other hand, already had a well-developed feeder network with hubs in Minneapolis and Detroit for its oriental routes. This carrier is also one with a reputation for negotiating very flexible work rules with its unions, providing another rationale for the stellar efficiency performance. Another reason for the relatively high efficiency 
of Pan Am, which ceased operations in 1991, and TWA, which filed for bankruptcy in the same year, is that both have relatively long average stage lengths. Since their network remained relatively unchanged during the sample, very little within variation of stage length remains after the within transformation. The efficiency effect may be an artifact of long haul flights which are not being controlled for adequately due to the low explanatory power of stage length.

The four European carriers had approximately a $0.18 \%$ average annual increase in technical efficiency over the sample period. This can be added to the $2.4 \%$ average annual technological change to yield nearly the same rate of productivity growth as experienced by U.S. carriers. This finding is potentially misleading, however, as there are considerable differences among firms. British Air shows a $2 \%$ annual increase in technical efficiency, while the average for other European carriers is a $0.7 \%$ average annual decline in technical efficiency. Under the Thatcher government, British Air was reorganized as part of an economy-wide move toward privatization of national industries and was eventually sold in January 1987. During this period, neither the French, German, or Italian governments made significant moves toward increasing private interests in their near total government enterprises. In fact, the French and Italians have maintained a high level of explicit subsidies. ${ }^{6}$ The difference also appears to be reflected in the different attitudes toward intraEuropean bilateral agreements: Great Britain has been a strong proponent of liberalization, while France and Italy have been strongly against it.

There are large differences between the average technical efficiencies of European and American carriers. Table 4 shows that U.S. carriers were nearly $15 \%$ more efficient throughout the study period than European airlines (this efficiency gap is nearly the same across all three of our estimated models). Figure 1 dissaggregates technical efficiency scores for the European carriers and compares them to the U.S. average. Technical efficiency levels are also projected through 1996. This provides a reasonable first estimate of the relative competitive advantage of individual European carriers. For Air France, Lufthansa and Alitalia, one possible reason for the declining technical efficiency levels is the loss of feeder

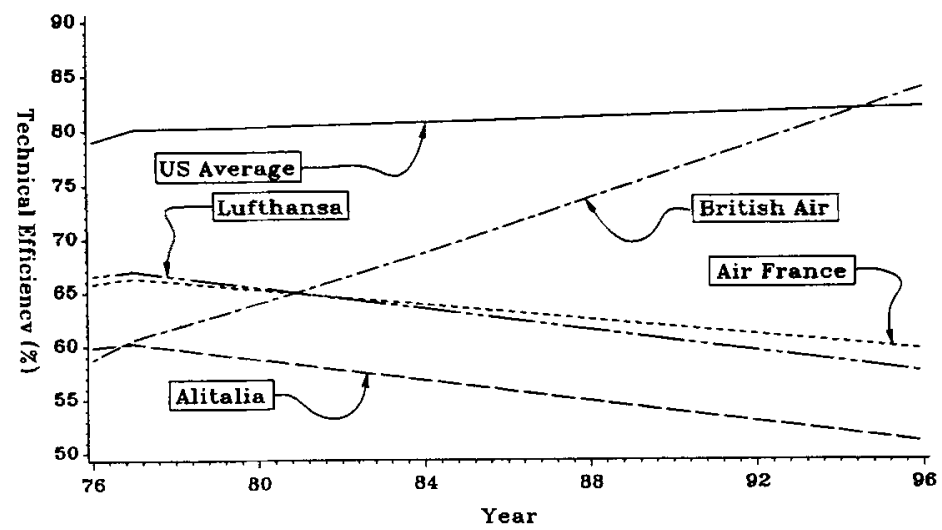

Figure 1. Estimated and projected levels of technical efficiency. 
traffic in the United States as American carriers increasingly began offering their own international service. The figure also illustrates British Air's substantial reduction in inefficiency. British Air's technical efficiency passes Air France in 1981, the worst of the U.S. carriers (Eastern) in 1984, and were trends to continue, the U.S. average in 1993.

Although point estimates of time trends in efficiencies suggest heterogeneity among carriers in Europe and in the United States, further examination reveals highly significant differences in levels, but no statistically significant differences in trends among all carriers $\left(F=1.28, v_{n}=11, v_{d}=99\right)$. Whether additional time periods and a larger number of European firms will provide more precise estimates of heterogeneous firm-specific trends or homogeneous firm-specific trends in efficiency is unclear.

As mentioned (note 2), measurement of allocative distortions is not carried out in this research. The possibility exists that the magnitude of allocative inefficiency is such that it offsets the differences in technical efficiency between the U.S. and European industries. However, evidence on the U.S. carriers suggests that the magnitude of allocative distortions is substantially smaller than the fifteen percent technical inefficiency differences between U.S. and European carriers during our study period (Sickles, Good, and Johnson [1986]; Sickles [1987]; Good, Nadiri, and Sickles [1992]). Comparable studies are yet to be completed for the European carriers. Consequently, the public policy implications of our research are viewed in absence of such large countervailing allocative distortions.

The opening up of competition in Europe is likely to pressure firms to eliminate much of this efficiency gap. Implications of eliminating the gap on the four large European carriers are reported in Table 5. Since these four carriers produce approximately half of the output of Association of European Airlines members, we can double the figures in this table to get a rough idea as to what the implications would be for all of Europe. We find that bringing all European airlines up to the U.S. performance average in 1986 would have saved the entire European airline industry approximately $\$ 4$ billion (in 1986 prices) annually which is about $16 \%$ of total operating costs. This is a minimum estimate since it does not include the costs of allocative inefficiency. Were output to remain fixed, such a

Table 5. Within estimates of cost and labor reductions resulting from elimination of technical efficiency gap between U.S. and European carriers.

\begin{tabular}{lccccc}
\hline Year & $\begin{array}{c}\text { Total Operating } \\
\text { Cost }\end{array}$ & $\begin{array}{c}\text { Explicit } \\
\text { Subsidy }\end{array}$ & $\begin{array}{c}\text { Cost of } \\
\text { TE }\end{array}$ & $\begin{array}{c}\text { Workers } \\
\text { Eliminated }\end{array}$ & $\begin{array}{c}\text { Average } \\
\text { Wage (\$) }\end{array}$ \\
\hline 76 & $5,436$. & $*$ & 875.64 & $19,207$. & $11,873$. \\
77 & $6,371$. & 101.31 & $1,047.62$ & $21,748$. & $14,989$. \\
78 & $7,969$. & 118.22 & $1,311.92$ & $22,244$. & $18,297$. \\
79 & $10,160$. & 112.23 & $1,669.74$ & $22,240$. & $21,706$. \\
80 & $12,328$. & 95.84 & $2,026.60$ & $22,085$. & $26,094$. \\
81 & 11.390. & 71.75 & $1,877.01$ & $21,087$. & $23,453$. \\
82 & $10,642$. & 76.43 & $1,767.41$ & $19,858$. & $23,001$. \\
83 & $10,663$. & 54.49 & $1,773.57$ & $20,000$. & $22,646$. \\
84 & $11,267$. & $*$ & $1,843.50$ & $20,421$. & $22,032$. \\
85 & $11,850$. & $*$ & $1,944.02$ & $21,086$. & $21,946$. \\
86 & $12,433$. & $*$ & $2,022.27$ & $21,083$. & $25,342$. \\
\hline
\end{tabular}

* Missing data

All amounts are in \$ millions unless otherwise stated. 
change could lead to the displacement of approximately $16 \%$ of the entire European airline workforce, or about 42,000 workers. Cost savings from such a $16 \%$ reduction in labor and other inputs could compensate displaced workers much the way that special provisions in U.S. unemployment insurance were established. However, there are two countervailing forces which should be considered in subsequent analyses. First, the input mix is likely to change. Second, demand for air travel appears to be fairly elastic. There has been a large increase in air travel with accompanying increases in employment in the U.S. airline industry due to fare reductions accompanying deregulation, even though labor intensities have fallen. On the other hand, the potential for output increases in the European airlines may be lessened by the presence of substitute transportation modes, particularly the railroads. Unlike in the United States, these may offer up substantial competition to intra-European air travel which may mitigate the scope for increasing output through fare reductions.

\section{Summary and Concluding Remarks}

This paper has analyzed technical efficiencies and productivity growth rates for four European and eight American air carriers using three alternative estimators. While nominal efficiency measures are fairly different across these estimators, the properties of technology and the estimation of an efficiency gap between European carriers are rather stable. Eliminating the efficiency gap brings with it a savings on the order of $\$ 4.5$ billion per year and a displacement of about 42,000 workers across the European industry.

As the title of our paper indicates, this is a first look at a very rich set of data that are continuing to be collected as well as a first look at somewhat reduced form explanations of the sources technical efficiency differences between Europe and America. As our European carrier list becomes more exhaustive, as we extend our time period to the early $1990 \mathrm{~s}$, and as we augment the European and American carriers with the remaining major world carriers, we anticipate being able to examine more structural explanations for the presence of technical and allocative distortions. The role that differing regulatory and institutional constraints have on the evolution of the international airline industry and how changes in these constraints will impact the survival propensities of particular carriers is yet another issue on which we will focus subsequent research.

\section{Acknowledgment}

A previous version of this paper was prepared for the National Bureau of Economic Research's Summer Workshop on Franco-American Productivity. The authors would like to thank the C.V. Starr Center, INSEAD, and Indiana University for financial support and John Meyer and seminar participants at the Usiversity of Toulouse and the Catholic University of Louvain for helpful comments. Special gratitude is extended to J. Mairesse and an anonymous referee for criticism which strengthened earlier drafts considerably. Purvez Captain, Cynthia Huebner and Michalene Reilly supplied crucial research assistance.

\section{Notes}

1. For a survey of the institutional setting surrounding U.S. deregulation, European liberalization, and the international airline industry the reader is referred to Bailey, Graham, and Kaplan [1985], de Murias [1990], and Kaspar [1991]. For an early empirical study of European and U.S. airlines see Barla and Perlman [1989]. 
2. Substitution elasticities are unity for the Cobb-Douglas. Caves et al. [1984] and Sickles et al. [1986] both estimate elasticities of substitution of between -0.1 and 0.5 , although they estimate cost and profit functions and their inputs are defined somewhat differently. Still, Madalla [1979] notes that measurement of technological change and efficiency are quite insensitive to the choice of functional form of production since both of these properties are related to shifts of the isoquants rather than their shapes. This initial study focuses on technical efficiency and leaves the analysis of allocative distortions for future research.

3. The empirical specification outlined in Section 4 includes a quadratic time effect that is common to all firms. All firm-specific productivity growth rates must be adjusted accordingly to also include the common time derivative of this second-order time effect.

4. Returns to density is based on the elasticity of output with respect to a proportionate increase in the inputs, $K, L$ and $M$, while holding other variables fixed. Returns to scale, is based on a proportionate increase in inputs and network density which increases when the number of route kilometers in the network (NET) falls. Note that these are not comparable to the returns to density and scale constructed by examining the ray average costs of producing ton miles of service and serving destinations. The interpretation of network in a single output study such as this is a characteristic of the output, which although potentially endogenous to firm effects, is nonetheless not interpreted as a separate output.

5. Following Nishimizu and Page [1982] we use the term technological change to describe the rate of increase of the efficient production technology (in our notation, measured by changes in the $\alpha_{t}$ over time). Productivity growth includes both technological change and reductions in technical inefficiency.

6. Explicit subsidies include only overt transfers from the government to cover operating losses. Other transfers do occur, such as government purchases of stock at unreasonably high prices, favorable rents for the use of government facilities, etc.

\section{References}

Baily, E.E., D.R. Graham, and D.P. Kaplan. (1985). Deregulating the Airlines. MIT Press.

Barla, P. and S. Perelman. (1989). "Technical Efficiency in Airlines under Regulated and Deregulated Environments." Annales de l'Economie Publique Social et Cooperative, 60, No. 1.

Caves, D.W., L.R. Christensen, and W.E. Diewert. (1982). "Output, Input and Productivity Using Superlative Index Numbers." Economic Joumal 92, 73-96

Caves, D.W., L.R. Christensen, and M.W. Tretheway. (1984). "Economies of Density versus Economies of Scale: Why Trunk and Local Service Airline Costs Differ." Rand Journal of Economics 14, 471-489.

de Murias, R. (1990). The Economic Regulation of International Air Transport. Jefferson, NC: McFarland. Cornwell, C., P. Schmidt, and R.C. Sickles. (1990). "Production Frontiers with Cross-Sectional and TimeSeries Variation in Efficiency Levels." Journal of Econometrics 46, 185-200.

Good, D.H., M.I. Nadiri, and R.C. Sickles. (1991). "The Structure of Production, Technical Change and Efficiency in a Multiproduct Industry: An Application to U.S. Airlines." National Bureau of Economic Research Working Paper 3939.

Good, D.H., and E.L. Rhodes. (1991). "Productive Efficiency, Technological Change and the Competitiveness of U.S. Airlines in the Pacific Rim." Journal of the Transportation Research Forum 31, 347-358.

Hausman, J.A., and W. Taylor. (1981). "Panel Data and Unobservable Individual Effects." Econometrica 49, 1377-1399.

Heston, A., and R. Summers. (1988). "Comparisons of Price and Gross Domestic Product for Several Countries," Review of Income and Wealth, 34, 1-28.

Kaspar, D.M. (1991). Deregulation and Globalization: Liberalizing International Trade in Air Services. Arnerican Enterprise Institute. Cambridge MA: Ballinger.

Madala, G.S. (1979). "A Note on the Form of the Production Function and Productivity." In Measurement and Interpretation of Productivity. National Research Council. Washington, DC: National Academy of Sciences, pp. 309-317.

Nishimizu, M., and J.M. Page. (1982). "Total Factor Productivity Growth, Technological Progress and Technical Efficiency Change." The Economic Journal 92, 920-936.

Sickles, R.C. (1987). "Allocative Inefficiency in the U.S. Airlines: A Case for Deregulation." In Ali Dogramaci (ed.), Studies in Productivity Analysis, Vol. 7. Boston: Kluwer-Nijhoff, pp. 149-162.

Sickles, R.C., D. Good, and R. Johnson. (1986). "Allocative Distortions and the Regulatory Transition of the U.S. Airline Industry." Journal of Econometrics 33, 143-163. 